\title{
TRANSIÇÕES, PRAZER E DOR NO TRABALHO DE ENFERMAGEM
}

\author{
José Humberto Viana Lima Júnior \\ Doutor em Administração pela FGV-EAESP e Professor Adjunto da FEA-UFJF. \\ E-mail: humberto@fea.ufjf.br \\ Angelo Brigato Ésther \\ Mestre em Administração pela UFMG e Professor-Assistente da FEA-UFJF. \\ E-mail: angelo@fea.ufjf.br
}

RESUMO

O artigo, fundamentado nas premissas teóricas sobre relações de trabalho, em especial em algumas variáveis que integram a categoria microssocial - organização do trabalho e condições de trabalho -, aliadas às contribuições da Escola Dejouriana, que analisa os temas do prazer e do sofrimento vinculados ao trabalho, procura desvendar o processo de desgaste/prazer no trabalho dentro de um hospital universitário, por meio do discurso dos trabalhadores de enfermagem ali atuantes, buscando captar suas realizações, dificuldades, alegrias, tramas e defesas, angústias, contradições, a luta pelo poder, as vivências subjetivas, os silêncios. Em suma, as transições da enfermagem de anjo de branco a profissional têm sido marcadas por preconceitos, desgaste, sofrimento e luta por espaço laboral. Abandonando a posição de saber periférico e vulnerável, assistimos, atualmente, ao esforço dos trabalhadores de enfermagem para a construção de uma nova imagem que contempla estratégias de revalorização do estatuto profissional, controle da formação, das carreiras e dos conteúdos do trabalho para que se tornem agentes privilegiados e ativos na melhoria das condições de saúde

da comunidade e propulsores de novas idéias para o avanço da gestão nas organizações hospitalares.

\section{ABSTRACT}

This article aims at the understanding of the factors linked to the genesis of pleasure and suffering as they are experienced by nursing workers in their labor performance. Based on the premises of labor relations, focusing the work organization and the working conditions, allied to contributions from Christophe Dejours, who analyzes the themes of pleasure and suffering within the work, we brought into evidence the particular aspects of the relationship between labor and suffering/pleasure process expressed by nursing workers who work in both public and universitarian hospital. Concerning the nursing trajectory from white angel to a professional, we could observe that it has been marked by conflicts, preconception, suffering and battles for labor space. Abandoning the position of peripheral and vulnerable knowledge, we verify nowadays the efforts of the nursing workers to construct a new image that contemplates strategies of revalorization of the professional statute, self-developing control, a motivating career plan and work contents based on new

paradigms, thus becoming privileged and active actors to improve community health conditions and propellents of new ideas in order to implant a vanguard administration model in the hospital organizations.

\section{PALAVRAS-CHAVE}

Trabalho de enfermagem, prazer e dor, transições, relações de trabalho, gestão hospitalar.

Nursing labor, pleasure and suffering, transitions, labor relations, hospital management. 


\section{INTRODUÇÃO}

Baseados nas premissas teóricas sobre relações laborais, aliadas às contribuições da Escola Dejouriana, que analisa os temas do prazer e do sofrimento vinculados ao trabalho, procuraremos desvendar o processo de desgaste/prazer vivenciado pelos profissionais da área da enfermagem. $\mathrm{O}$ trabalho em ambiente hospitalar é considerado rico, estimulante e heterogêneo. Abarca, simultaneamente, no entanto, atividades insalubres, penosas e difíceis para todos os atores, dentre os quais destacamos os trabalhadores de enfermagem.

A elevada tensão emocional advinda do cuidado direto de pessoas fisicamente doentes ou lesadas, associada às longas jornadas, à baixa remuneração, ao freqüente emprego duplo, ao desenvolvimento de tarefas desagradáveis, repulsivas e aterradoras, gera danos à saúde, propiciadores de acidentes, de encurtamento de vida ou até mesmo de morte prematura dos trabalhadores de enfermagem. Sem escolha, submetem-se a relações, organizações, condições e ambientes que contribuem significativamente para um sofrimento inevitável e ubíquo, que idealmente demandaria ser gerenciado pelos trabalhadores em proveito de sua saúde e qualidade de vida.

A indagação que fazemos reside em como esses profissionais podem buscar encantamento num mundo marcado precipuamente pela dor, tristeza e morte, tornando o ambiente laboral um espaço onde subsistam a alegria, o lúdico e o prazer. Na realidade, nenhuma atividade está isenta de propiciar satisfação ou desgaste físico e mental, mas, na dependência de fatores decorrentes de sua própria natureza, de sua forma de organização e de condições de realização, estes poderão estar presentes em maior ou menor grau.

Não podemos negar a natureza de determinado tipo de trabalho, mas podemos minorá-la ou empreender ações que contribuam para a melhoria de suas condições e organização, a fim de permitir ao trabalhador o exercício da criatividade e a prática do lúdico, transformando o sofrimento patogênico em sofrimento criativo, objetivando o prazer. A relevância deste estudo reside em acompanhar o cotidiano do pessoal de enfermagem sob a perspectiva da vivência, de como realmente é, como se dá, e não de como deveria ser, contemplando fatores que estão na gênese do desgaste e do prazer no trabalho hospitalar.

\section{ENFERMAGEM: TRABALHO, CUIDADO E RISCO}

Ao longo da História, o ambiente laboral tem sido causa de mortes, doenças e incapacidade para uma considerável parcela de trabalhadores. Entendido como o conjunto de condições de vida no local de trabalho, en- globa tanto as características do próprio lugar (dimensões, iluminação, aeração, presença de poeiras, gases ou vapores e fumaças, dentre outros) quanto os elementos conexos à atividade em si (tipo de trabalho, posição do trabalhador, ritmo do trabalho, ocupação do tempo, horário diário, semanal, sistema de turnos, alienação e nãovalorização do patrimônio intelectual e profissional) (Oddone, 1986).

\section{AO LONGO DA HISTÓRIA,} O AMBIENTE LABORAL TEM SIDO CAUSA DE MORTES, DOENÇAS E INCAPACIDADE PARA UMA CONSIDERÁVEL

\section{PARCELA DE TRABALHADORES.}

Dependendo da intensidade e também do tempo de contato dos indivíduos com esses elementos, podem resultar formas variadas de danos à saúde dos trabalhadores: da sensação indefinida de desconforto e sofrimento às doenças profissionais clássicas e aos acidentes de trabalho. Conforme Lopes et al. (1996), os trabalhadores submetem-se sem escolha às relações, organizações, condições e ambientes, expondo-se fisicamente à poeira, vapores, gases, calor, barulhos, acidentes, jornadas excessivamente longas, elementos sobre os quais não detêm nenhum controle.

Atualmente, sabemos que a atividade em ambiente hospitalar abrange uma série de fatores geradores de insalubridade e penosidade, produzindo agravos à saúde do trabalhador. Nesse tipo de organização, dificilmente existe a preocupação em proteger, promover e manter a saúde de seus funcionários. Sem dúvida, trata-se de uma situação paradoxal, porque, ao mesmo tempo em que o hospital tem como missão salvar vidas e recuperar a saúde dos indivíduos enfermos, favorece o adoecer das pessoas que nele trabalham.

Nesse contexto, enfermeiros, técnicos e auxiliares de enfermagem expõem sua saúde e segurança a condições que favorecem o aparecimento de acidentes, sofrimentos e doenças. Observamos que, apesar da possibilidade de mensuração, avaliação, prevenção ou até mesmo de eliminação dos riscos, estes permanecem afetando sobremaneira a saúde dos trabalhadores no ambiente laboral contemporâneo.

A preocupação com os problemas que emergem da relação trabalho-saúde inerente aos profissionais que exercem suas atividades em hospitais vem despertando o 
interesse de pesquisadores devido aos aspectos de penosidade e sofrimento referentes ao cuidar de pessoas doentes, além dos riscos do ambiente de trabalho. A maioria dos estudos que enfoca essa temática esbarra nos limites do paradigma positivista, uma vez que se embasa na concepção hegemônica multifatorial do processo saúde-doença. Nessa concepção, tais estudos buscam apreender os riscos e morbidades específicos a que estão expostos os trabalhadores de enfermagem segundo uma visão restrita, ou seja, como agentes presentes no ambiente de trabalho. No que concerne às pesquisas que enfocam o desgaste mental relacionado ao trabalho de enfermagem, podem-se citar a abordagem psicossocial ou materialista histórica e dialética de Menzies (s.d.), na Inglaterra, e a de Pitta (1990) e Silva (1996), no Brasil.

Num estudo com trabalhadores de enfermagem de um hospital londrino, Menzies (s.d.) ressalta que o serviço de enfermagem sofre o impacto total, de modo imediato e concentrado, das tensões, angústias e conseqüente desgaste mental que advêm do cuidar diretamente de pessoas fisicamente doentes ou lesadas. O lidar cotidiano com doenças e morte imprime um fluxo de atividades que compreende a execução de tarefas agradáveis ou não, repulsivas e aterradoras, fazendo emergir sentimentos muito fortes e contraditórios na enfermeira: piedade, compaixão e amor; culpa e ansiedade; ódio e ressentimento contra os pacientes e até mesmo inveja do cuidado oferecido ao doente.

Em seu trabalho, Menzies (s.d.) confirmou como a organização parcelada do trabalho de enfermagem e a desqualificação, que esvazia os seus significados, afetam negativamente a vida psíquica das enfermeiras e propiciam o surgimento de um sistema socialmente estruturado de defesas psicológicas. Se, por um lado, esse fato proporciona às profissionais um certo grau de desempenho rotinizado e sistematizado, por outro, gera perdas relevantes para a vitalidade de seu psiquismo individual e para a qualidade do trabalho que realizam.

As contribuições provenientes do estudo de Menzies (s.d.) são fundamentais para os avanços na organização do trabalho de enfermagem e para a promoção de saúde psicossocial - incluída aí a realização profissional da categoria. É curioso notar, no entanto, o fato de ainda não terem sido levadas em consideração e amplamente aproveitadas para tais objetivos.

A investigação de Pitta (1990) visa mostrar que o sofrimento psíquico daqueles que trabalham com a dor e a morte do outro decorre da própria natureza e das formas de organização desse trabalho essencial e diuturno, evidenciado por sintomas e sinais orgânicos e psíquicos inespecíficos. Assim, a autora, buscando nexos de causalidade entre a organização e a divisão do trabalho e o sofrimento psíquico dos trabalhadores em uma investigação empírica desenvolvida num hospital geral, analisa alguns elementos, dentre os quais podem ser destacados a natureza do trabalho, a divisão das tarefas, o ritmo, o controle, a pressão das chefias, a jornada, o gênero, o estrato social e a qualificação.

Silva (1996) procura, por meio de um estudo fundamentado no materialismo histórico e dialético, enfocar a relação trabalho-saúde dos trabalhadores de enfermagem de um hospital público e universitário. Com esse objetivo, reproduz o referencial teórico-metodológicooperacional construído por Laurell e Noriega (1989), que correlaciona os processos de trabalho e condições de desgaste. O modelo implica um grande desafio por contemplar a dificuldade de se entender o fenômeno do desgaste mental que ocorre na interação do indivíduo com o trabalho, já que trata de aspectos objetivos, subjetivos e intersubjetivos.

Nesse sentido, tomando como base as contribuições de Laurell e Noriega (1989), os quais definem o desgaste como perda de capacidade potencial e/ou efetiva, corporal e psíquica, Silva (1996) analisa as diferentes cargas a que estão expostos os trabalhadores de enfermagem, gerando um perfil de desgaste característico. As cargas são classificadas como de materialidade externa ou interna. As cargas de materialidade externa a que estão sujeitos os trabalhadores de enfermagem podem ser agrupadas em físicas, biológicas, químicas e mecânicas. As cargas de materialidade interna a que estão submetidos os trabalhadores de enfermagem podem ser caracterizadas em fisiológicas e psíquicas.

De acordo com Laurell e Noriega (1989), uma vez que as cargas presentes no ambiente hospitalar são responsáveis pelos desequilíbrios que conduzem aos processos de desgaste irreversíveis, aos acidentes, às doenças e à morte prematura, assume acentuada importância o papel protagonista dos trabalhadores na transformação da realidade e na construção de uma prática social distinta, visto que consideram inegável a relação entre conhecer e transformar.

Nesse contexto, os trabalhadores de enfermagem devem buscar maior engajamento, articulação e conhecimento com relação à base técnica, à organização e à divisão do trabalho, para que tenham condições de transformálas e adaptá-las aos seus equipamentos fisiológicos e psicológicos.

\section{RELAÇÕES DE TRABALHO E ASPECTOS PSICODINÂMICOS DA RELAÇÃO HOMEM-TRABALHO: DESVENDANDO O PRAZER E O SOFRIMENTO}

Há muito tempo sabemos que o trabalho, quando executado em ambientes insalubres e penosos, causa doenças, encurta a vida ou mata os trabalhadores. É histórico o nexo causal entre o trabalho e o sofrimento 
físico, colocando a ênfase da discussão sobre o corpo como lugar depositário de doenças provocadas pelas condições de trabalho.

Numa nova abordagem, Dejours (1994) revela que o desgaste no trabalho não deveria ser reduzido apenas às pressões físicas, químicas, biológicas ou mesmo psicossensoriais e cognitivas do posto de trabalho habitualmente estudadas. Para o autor, é fundamental considerar a dimensão organizacional, centralizada na divisão das tarefas e nas relações de produção, contrapondo-se à concepção tradicional da ergonomia, baseada na análise das condições de trabalho.

A dimensão organizacional diz respeito às relações de trabalho que são, para Dejours (1992a, p. 75), "todos os laços humanos criados pela organização do trabalho: relações com a hierarquia, com as chefias, com a supervisão, com os outros trabalhadores - e que são às vezes desagradáveis, até insuportáveis". Considerando essa realidade, o trabalho tanto pode fortalecer a saúde mental do trabalhador como também favorecer a constituição de distúrbios, resultando em manifestações psicossomáticas e de conduta, no que se refere à psicopatologia do trabalhador e do próprio trabalho.

Embora o termo relações de trabalho venha sendo adotado com sentidos teóricos específicos conforme a área do conhecimento e a abordagem metodológica, inclusive entre pesquisadores de uma mesma área (Fleury e Fischer, 1987), a Administração definiu abrangência própria a seu nível de análise - micro - e a seu objeto particular de estudo - as organizações -, considerando que o enfoque do processo de trabalho, adotando uma perspectiva macro, é muito amplo e generalizante para o entendimento das relações particulares que se desenvolvem cotidianamente no interior das organizações para a realização do trabalho.

Nesse sentido, a obra de Fleury e Fischer (1987) representa um marco nas análises teóricas e metodológicas do assunto. Para as autoras, as relações de trabalho nascem das relações sociais de produção, constituindo a forma particular de interação entre agentes sociais que ocupam posições opostas e complementares no processo produtivo: os trabalhadores e os empregadores. Na sua obra, Fischer (1987, p. 20) afirma que "as relações de trabalho são uma das formas de relacionamento social e, por isso, expressam características da sociedade mais ampla", acrescentando que "os padrões que assumem em quadros históricos, conjunturais e setoriais dados são resultantes dessas características redefinidas para os contextos em que emergem".

Dessa forma, a autora ressalta que, em termos de pesquisa e conhecimento, deve-se contemplar o espaço social e político em que as relações de trabalho se realizam: a organização do processo de trabalho, a elaboração das políticas administrativo-organizacionais e a prática cotidiana dos agentes sociais em relação.
Portanto, ao se considerar o trabalho como uma categoria social sujeita a múltiplas determinações, o conceito de relações de trabalho adquire maior amplitude com a inserção de outras variáveis significativas da sociedade (Laurell, 1985). De acordo com Siqueira (1991, p. 21), "as relações de trabalho que ocorrem no interior de uma organização não podem ser explicadas apenas por variáveis internas à organização, dependendo de variáveis do ambiente organizacional próprio e de variáveis da sociedade".

\section{A SITUAÇÃO DOS HOSPITAIS É}

PARADOXAL: AO MESMO TEMPO

EM QUE TÊM COMO MISSÃO

SALVAR VIDAS E RECUPERAR

A SAÚDE DOS INDIVÍDUOS

ENFERMOS, DIFICILMENTE TÊM

A PREOCUPAÇÃO DE PROMOVER

E MANTER A SAÚDE DE

SEUS FUNCIONÁRIOS.

Ao definir relações de trabalho, a autora adota como categorias de análise as categorias macrossociais, organizacionais e microssociais (Siqueira, 1991). No que diz respeito ao nível macrossocial, são definidas para análise as variáveis tecnologia do trabalho, o mercado de trabalho e a organização político-sindical; no nível organizacional, a dependência em relação ao Estado e, na esfera microssocial, a organização do trabalho, a gestão da força de trabalho, as condições de trabalho e as formas de regulação de conflitos. Para os fins deste estudo, as variáveis organização do trabalho e condições de trabalho podem ser definidas da seguinte forma:

\section{- Organização do trabalho}

São as "maneiras de dividir e sistematizar as tarefas e o tempo entre grupos de trabalhadores; as especialidades decorrentes e as qualificações exigidas; as sequiências, os ritmos e cadências; a padronização e a autonomia; a participação do trabalhador na programação e o 'locus' de realização das tarefas" (Siqueira, 1991, p. 40).

\section{- Condições de trabalho}

Elas "implicam não só as condições ambientais e os 
riscos específicos envolvidos no trabalho dos grupos analisados, mas também a introdução da subjetividade do empregado, refletindo a representação de seu modo específico de trabalhar/desgastar-se incluindo a saúde mental e o stress" (Siqueira, 1991, p. 42).

Assim, tomando-se tais premissas teóricas sobre relações de trabalho, especificamente duas variáveis que compõem a categoria microssocial - organização e condições de trabalho -, objetivamos compreender como se projeta a relação sofrimento/prazer dos trabalhadores de enfermagem e como alguns deles se encaminham ao sofrimento patogênico e outros, ao sofrimento criativo.

Dejours e Abdoucheli (1994, p.137) distinguem dois tipos de sofrimento:

"Sofrimento criador e sofrimento patogênico. O último aparece quando todas as margens de liberdade na transformação, gestão e aperfeiçoamento da organização do trabalho já foram utilizadas. Isto é, quando não há nada além de pressões fixas, rígidas, incontornáveis, inaugurando a repetição e a frustração, o aborrecimento, o medo, ou o sentimento de impotência. Quando foram explorados todos os recursos defensivos, o sofrimento residual, não compensado, continua seu trabalho de solapar e começa a destruir o aparelho mental e o equilíbrio psíquico do sujeito, empurrando-o lenta ou brutalmente para a descompensação (mental ou psicossomática) e para a doença. Fala-se então de sofrimento patogênico.

O desafio real na prática, para a psicopatologia do trabalho, é definir as ações susceptíveis de modificar o destino do sofrimento e favorecer sua transformação (e não sua eliminação). Quando o sofrimento pode ser transformado em criatividade, ele traz uma contribuição que beneficia a identidade. Aumenta a resistência do sujeito ao risco de desestabilização psíquica e somática e funciona como um mediador para a saúde. Quando, ao contrário, a situação, as relações sociais de trabalho e as escolhas gerenciais empregam o sofrimento no sentido patogênico, o trabalho funciona como um mediador de desestabilização e da fragilização da saúde."

Dessa forma, sofrimento e prazer são provenientes da dinâmica interna das situações e da organização do trabalho, ou seja, são produtos dessa dinâmica, das relações subjetivas e de poder, das condutas e ações dos trabalhadores permitidas pela organização do trabalho.

Considerando a interface entre o conceito de relações de trabalho e as contribuições da Escola Dejouriana, procuraremos desvendar a realidade laboral dos trabalhadores de enfermagem do Hospital Universitário da Universidade Federal de Juiz de Fora (HUUFJF).

\section{O (DES)CONHECIDO TRABALHO DO PESSOAL DE ENFERMAGEM: O CASO DO HOSPITAL UNIVERSITÁRIO DA UFJF}

\section{Metodologia}

O objetivo central do estudo foi a identificação dos fatores que, na percepção dos enfermeiros, técnicos de enfermagem e auxiliares de enfermagem, têm implicações nos sentimentos de prazer e desgaste no trabalho.

Definimos como objetivos específicos a serem alcançados nesta pesquisa:

a) procurar relacionar sofrimento psíquico com as condições ansiogênicas e estressoras de determinadas formas de organização do trabalho;

b) explorar como os trabalhadores de enfermagem da instituição selecionada convivem e reagem em relação ao desgaste/prazer da sua prática diária na assistência de enfermagem;

c) contribuir para a discussão sobre a qualidade de vida no trabalho, sob a ótica do ambiente interno.

A pesquisa baseou-se em uma amostra intencional dos trabalhadores de enfermagem que trabalham em unidades de atenção direta ao paciente, exercendo suas atividades em diferentes unidades de internação e em turnos distintos. Foram entrevistados 14 enfermeiros (E), 13 técnicos de enfermagem (TE) e 9 auxiliares de enfermagem (AE). As opiniões, atitudes, valores e concepções, na ótica dos diferentes atores que acederam a ser entrevistados, permitiram retratar o trabalho de enfermagem no HUUFJF em sua complexidade e riqueza.

As unidades de atenção direta ao paciente enfocadas no presente estudo e o respectivo número de entrevistas são os seguintes: Serviço de Enfermagem de Clínicas de Homens, com sete entrevistados; Serviço de Enfermagem de Clínicas de Mulheres, com quatro entrevistados; Serviço de Enfermagem em Unidade de Terapia Intensiva, com três entrevistados; Serviço de Enfermagem de Cirurgias de Homens, com oito entrevistados; Serviço de Enfermagem de Cirurgias de Mulheres, com oito entrevistados e Serviço de Enfermagem de Pediatria, com seis entrevistados.

\section{A fala do trabalhador de enfermagem: expressão do desgaste e do prazer}

Com base nos testemunhos fornecidos pelos trabalhadores de enfermagem, procuramos analisar o cotidiano vivido em um ambiente hospitalar, visando à apreensão dos fatores que estão na gênese do desgaste e do prazer no trabalho. Os discursos apresentados a seguir são um jorrar espontâneo de idéias e sentimentos, fiel revelador da realidade sofrida, conflituosa e contraditória do mundo hospitalar, em especial do Hospital Universitário da Universidade Federal de Juiz de Fora (HU-UFJF). 


\section{Valorização da profissão perante a sociedade}

As trabalhadoras de enfermagem não se sentem valorizadas como funcionárias do hospital e se julgam discriminadas na sociedade por terem uma imagem vinculada a um anjo de branco, o símbolo da abnegação e do servir ao próximo, ou a uma pessoa de conduta moral incorreta, sempre se envolvendo com o staff médico.

"A imagem da enfermeira vem sofrendo uma mudança para melhor, porque até bem pouco tempo atrás éramos vistas como prostitutas ou irmãs de caridade, na visão geral do povo, ou, então, amante do médico. Hoje estamos buscando nosso lugar pela competência e pela eficiência." (Enfermeiro - Entrevista 14)

"Até bem pouco tempo atrás, a gente ouvia dizer que quem trabalhava na enfermagem era mulher de médico. Eu já tive diversos namorados que a primeira coisa que falava pra mim era que 'se você quiser continuar namorando comigo você sai dessa profissão'... então acabava com aquilo ali e pronto. Eu queria minha profissão..." (Técnico de Enfermagem - Entrevista 04)

Acrescentamos a essa realidade o fato de que, na percepção do senso comum, não se diferencia o E de qualquer pessoa que trabalhe aplicando injeções, dos agentes de saúde e, sobretudo, dos TEs e AEs.

"É uma profissão que não tem status, nós não temos status enquanto um profissional de nível superior, porque se confunde muito o auxiliar, o técnico e o enfermeiro, né?..." (Enfermeiro - Entrevista 19)

Constatamos que, dessas três imagens, a primeira mitifica (irmã de caridade/anjo de branco), a segunda vulgariza (prostituta/amante do médico) e a terceira simplifica o profissional enfermeiro (não-diferenciação do $\mathrm{E}$ perante as outras categorias).

Nos diversos relatos, pudemos perceber que já começam a ocorrer mudanças de mentalidade, mostrando que o trabalho do enfermeiro e da enfermagem está sendo mais reconhecido e apresentando maior diferenciação entre as diversas categorias, tanto pela comunidade que recorre aos serviços de saúde quanto pelos membros mais novos integrantes da equipe multiprofissional, destacando-se o médico.

\section{Remuneração e benefícios}

Em relação a planos de recompensa e benefícios, o HU-UFJF não oferece vantagens aos trabalhadores. Todos os entrevistados consideram o salário muito baixo, gerador de descontentamento e desânimo por não atender às necessidades de sobrevivência com decência e conforto. Uma parcela considerável tem no salário recebido a parcela principal do orçamento familiar ou é arrimo de família.

Em especial, os Es ressaltam que os salários da classe são muito baixos, se levadas em consideração a atividade e a responsabilidade que têm. Tal nível salarial levaos a assumir mais de um vínculo empregatício para ob- ter melhores condições de vida, o que reputam bastante estressante e cansativo.

"A questão salarial pesa muito, a maioria escolhe a profissão pra sustento, eu acho que é um peso muito grande, mas o que me satisfaz é o servir ao próximo, eu acho que é vital pra mim ser útil, isso me realiza, me deixa bem, me sinto em paz." (Enfermeiro - Entrevista 09)

\section{SOFRIMENTO E PRAZER SÃO} PROVENIENTES DA DINÂMICA INTERNA DAS SITUAÇÕES E DA ORGANIZAÇÃO DO TRABALHO, DAS RELAÇÕES SUBJETIVAS E DE PODER E DAS CONDUTAS E DAS AÇÕES DOS TRABALHADORES.

Os TEs e os AEs consideram que a remuneração que percebem é baixa. Acreditam, no entanto, que recebam muito mais do que se estivessem na iniciativa privada, conforme depoimento abaixo:

"Em relação ao lugar que eu trabalhava, o salário daqui é melhor; apesar de estar defasado, aqui é melhor." (Auxiliar de Enfermagem - Entrevista 06)

Os entrevistados não vêem possibilidades de promoção na carreira e salientam que lhes poderiam ser oferecidos benefícios extraordinários para minimizar a ansiedade inerente à capacidade de sustento da família e ao desencanto com a profissão.

\section{O ambiente físico do HU-UFJF: suas características e deficiências}

Mal planejado e mal equipado, carente de recursos tecnológicos específicos e falta de apoio logístico necessário a um desempenho eficiente, o ambiente físico do HU é apontado como um problema pela maioria dos entrevistados, acarretando desperdício de tempo e de energia, além de riscos de agravo à saúde.

"A estrutura nossa aqui é totalmente fora dos padrões, né? Rampas muito altas, escadas, realmente é muito desgaste... posto muito distante das enfermarias, então "cê anda quilômetros durante o dia, durante o plantão, sabe?" (Enfermeiro - Entrevista 03)

A falta de manutenção e de adequação das instalações também é considerada problemática em decorrência das repercussões sobre o conforto e os cuidados prestados aos pacientes, sendo um impeditivo para que as intervenções 
necessárias a um bom atendimento se realizem com eficiência e eficácia. As reclamações se estendem igualmente à inexistência de um refeitório e de uma sala de descanso para os funcionários.

Na concepção dos entrevistados, um local de trabalho agradável e funcional é percebido como essencial para o desempenho de suas atividades. Eles observam que a inadequação das condições físicas do ambiente interfere negativamente na realização do trabalho, principalmente se as características do local forem incompatíveis com o tipo de ação a ser executado, sendo causa de um grande desgaste e descontentamento.

\section{Os recursos humanos e materiais: a essência do cuidado}

Um fator apontado como facilitador do trabalho refere-se à organização do ambiente, que possibilita segurança aos profissionais e controle da assistência prestada aos pacientes sob sua responsabilidade. Em contraposição, os entrevistados afirmam que receber um plantão sem as condições necessárias - carência de materiais básicos e especializados e falta de funcionários - dificulta suas ações, sendo origem de muita tensão, irritabilidade, desespero e cansaço.

"Igual eu 'tô te falando, hoje só tem duas aqui, se uma adoecer ou passar mal, nem pode, a gente não tem o direito de adoecer, porque se uma adoecer (risos) a outra vai ficar sozinha e aí como é que 'cê vai trabalhar, né? Fora material que não tem, você tem que fazer um curativo, não tem pinça, 'cê tem que ficar improvisando, paciente quer fazer xixi, sabe o que é que a gente faz, não tem comadre, a gente pega bacia, às vezes, nem luva tem, fica improvisando, pega um par, então uma mão usa, depois pega a outra guarda pra depois (risos), tem que dar banho no paciente, mas não tem uma bacia, isso também é horrível, atrasa o teu serviço e é ruim pro paciente, né? Porque "cê não vai atender o paciente bem como ele tem que ser atendido, é uma tristeza..." (Técnico de Enfermagem - Entrevista 31)

Os entrevistados deixaram evidente que a falta de condições materiais e tecnológicas é tida como muito desgastante, originando um sentimento de impotência ao tentar e não conseguir aquilo de que necessitam. Obter aquilo de que se precisa depende da disposição em "correr atrás" e de uma certa dose de "criatividade" para economizar itens não disponíveis na quantidade suficiente, além de adaptarem materiais mais caros para uso em determinados procedimentos.

O prazer e a alegria em concretizar intervenções corretas e eficazes são suplantados pelo sacrifício e pelo desespero de não conseguir aquilo de que necessitam, impossibilitando o desenvolvimento de suas atividades de maneira melhor e em menor espaço de tempo.

"Como é que você vai ter prazer em trabalhar, se você não tem como fazer bem feito, eu acho que o prazer 'tá em fazer aquilo que você gosta, mas fazer bem feito." (Auxiliar de Enfermagem - Entrevista 25)

Diversos Es manifestaram dúvidas, preocupação e ansiedade devido a alguns equipamentos e aparelhos não estarem em boas condições de uso e não apresentarem dados/informações confiáveis, podendo comprometer a saúde e/ou o pronto restabelecimento dos pacientes. Em casos de urgência/emergência, isso potencializa um estado de angústia, nervosismo e incapacidade, devido à premência de uso de um determinado aparelho que não funciona, tendo que solicitar a outro setor, que também não dispõe do aparelho em condições adequadas de uso, pouco podendo ser feito pelo paciente.

"O trabalho é cansativo, por exemplo, material fora de lugar, a dificuldade de você encontrar material, a organização do teu setor, entendeu? O CTI é um setor que tem que ter um controle excelente, porque na hora de uma emergência você fica muito apreensivo, né?... Se você, às vezes, perde um paciente por falta de organização, traz muita revolta, você não sai bem do plantão, não... não dá certo!!!" (Técnico de Enfermagem - Entrevista 36)

Especificamente em relação à falta de recursos humanos, observamos que os entrevistados são unânimes em afirmar que existe excesso de tarefas superpostas e repetitivas compartilhadas pelo pessoal disponível. As solicitações múltiplas e inesperadas impõem um ritmo mais acelerado e intenso de trabalho que conduz ao esgotamento físico e mental.

"'Cê vê hoje, até o meio-dia somos três, depois do meio-dia somos duas, então a gente faz tudo, tem paciente que depende da gente pra tudo, a gente dá remédio, alimentação, leva paciente ao banheiro... Chega em casa aquele farrapo humano (risos)." (Técnico de Enfermagem - Entrevista 31)

O quadro de pessoal do HU-UFJF apresenta-se bastante reduzido devido ao grande número de aposentadorias e à inexistência de concursos para preenchimento das vagas. Esse cenário indica a saída de profissionais experientes, a não-contratação de novos e a sobrecarga dos remanescentes, que ficam impossibilitados de atuar em consonância com padrões de qualidade desejados e de atender às exigências do trabalho. Muitos Es, TEs e AEs revelam que foram obrigados a se afastar das suas atividades - áreas de atuação e horários de suas predileções - por causa do desgaste sofrido pela falta de suporte para executar o trabalho e a cobrança por resultados. Denunciaram que as condições de sobrecarga de trabalho e a inexistência de material levam a revolta, angústia e stress, como evidenciado no depoimento abaixo:

"Teve uma época que eu 'tava trabalhando muito, falta de funcionário, sabe? Daí eu chegava a desmaiar e eu não tinha nada, eu parava assim, se bobeasse eu até caía no chão, as colegas é que tinham que me atender 
aqui, ficar me socorrendo, aqui (risos) e não era um problema de saúde, não, algum problema sério, era stress. Depois fiquei uns tempos em casa, melhorei, voltei pra outro setor, não tive mais." (Técnico de Enfermagem Entrevista 31)

Alguns Es comentam que é necessário apreender conceitos de Administração e de Gestão Hospitalar objetivando o desenvolvimento de habilidades de negociação, comunicação e participação, a fim de atuar efetivamente em conjunto com a Direção do Hospital no estabelecimento das metas do HU-UFJF. Sentem que precisam envidar esforços para controlar e manter seu poder sobre as decisões que interferem em seu trabalho, visto que as ações estratégicas têm ficado a cargo dos diretores, invariavelmente médicos, os quais não apresentam uma visão administrativa ampla que atenda às expectativas, aos interesses e aos objetivos institucionais.

\section{Características das áreas de atuação da equipe de enfermagem}

Em face de suas peculiaridades e especificidades, determinadas áreas de internação foram mencionadas pelos entrevistados como sendo locais saudáveis e prazerosos de se trabalhar, enquanto outras são apontadas como geradoras de desgaste e tensão, repercutindo negativamente no equilíbrio físico e mental.

Os trabalhadores revelam que o ambiente do CTI gera sofrimento, tensão e medo, pois se fica em contato direto com o objeto de trabalho, o corpo individual do paciente doente, que sofre, que sente dor e que não se recupera.

$\mathrm{O}$ freqüente assistir à morte dos pacientes foi considerado uma das situações mais penosas de ser enfrentada no CTI. Declararam que a perda dos pacientes jovens e das crianças, bem como a daqueles pacientes que estão há muito tempo internados na unidade, com quem se acostumaram a conviver, são as mais difíceis de elaborar. Podemos perceber essa conotação nos discursos que se seguem:

"De insatisfação no CTI é a morte, você lidar constantemente com a morte, é muito difícil, né? O doente vem, vai... e fica o luto. Fica o luto pra enfermagem, a enfermagem lidou com o doente, tratou daquele doente e depois ele vai embora... o vazio fica mesmo pra enfermagem, porque a enfermagem passou as 24 horas do dia com aquele doente, satura muito lidar com isso..." (Técnico de Enfermagem - Entrevista 35)

Por outro lado, trabalhar arduamente e pacientemente para tirar alguém de um coma profundo, obter sucesso nas manobras de ressuscitação em uma parada cardíaca ou reverter um choque anafilático é considerado algo maravilhoso, extraordinário e incrível, constituindo motivo de regozijo, prazer e realização no trabalho.

Para muitos entrevistados, a pediatria é percebida como um local onde prepondera a alegria pelo fato de se dedicarem às crianças, proporcionando carinho, proteção e bem-estar, tendo maiores possibilidades de particularizar e personalizar a atenção e os cuidados de enfermagem. Entristece-os profundamente, desencadeando desespero e descontrole emocional, a ocorrência de situações anômalas e o lidar com crianças que demandam atenção e cuidados especiais, na ausência de materiais e equipamentos adequados para prestar uma boa assistência.

\section{As TRABALHADORAS DE}

\section{ENFERMAGEM SE JULGAM}

DISCRIMINADAS POR TRÊS IMAGENS

ESTEREOTIPADAS: A PRIMEIRA

MITIFICA (IRMÃ DE CARIDADE/ANJO DE BRANCO), A SEGUNDA

VULGARIZA（PROSTITUTA/AMANTE DO MÉDICO) E A TERCEIRA

\section{SIMPLIFICA O PROFISSIONAL ENFERMEIRO (NÃO-DIFERENCIAÇÃO DO ENFERMEIRO PERANTE AS} OUTRAS CATEGORIAS).

"Trabalhar na pediatria é bastante estressante, principalmente porque você não sabe como agir diante de determinadas situações... e você acaba sofrendo junto, sabe? Aqui, na pediatria esse é o motivo da greve agora, a gente lida com infecção sem respirador, a gente não tem condições adequadas pra atender uma urgência, então você tem que se desdobrar pra conseguir manter... né? a criança viva, aí, na maioria das vezes a gente até transfere, então você tem que ficar pedindo ambulância, tem que pedir o resgate, sabe?" (Enfermeiro - Entrevista 03)

O Serviço de Clínicas de Homens engloba leitos para internação de pessoas portadoras de doenças infecto-contagiosas, sendo expresso pelos trabalhadores como um local propiciador de grande sofrimento físico e psíquico, por lidarem cotidianamente com pacientes críticos, o que implica duas possibilidades distintas: a de se ter resultado satisfatório e conseqüente melhora do quadro clínico e a da morte do paciente, o que significa trabalho "perdido".

"Aqui tinha muito óbito dos HIV, que nesse andar fica os pacientes HIV positivos, então tinha muito óbito, todos muito jovens. Já não 'tava agüentando mais olhar pra cadáver, de preparar corpo de paciente HIV, 'tava me depri- 
mindo muito, e agora, não sei se é esse coquetel, mas melhorou muito."(Auxiliar de Enfermagem - Entrevista 13)

De forma semelhante, o Serviço de Clínicas de Mulheres possui leitos para doenças infecto-contagiosas, tendo sido mencionado como uma área de trabalho penosa pela existência de casos graves e difíceis de se lidar como mulheres portadoras do vírus HIV, gerando uma sensação de tristeza e lamento pelas situações que vivenciam.

Os entrevistados apregoam que o prazer no trabalho advém primordialmente do fato de poderem assistir diretamente o paciente, prestando cuidados, acompanhando sua evolução clínica, da recuperação até a alta hospitalar. Eles afirmam que situações de urgência/emergência são bastante desafiadoras, proporcionando realização plena, quando logram êxito ao lidar com o risco iminente de vida. O convívio com o sofrimento e a dor do outro instaura conflitos e contradições inevitáveis, pois, apesar do envolvimento emocional intenso e o desgaste a que se submetem, gostam do que fazem, sentindo-se recompensados por poderem zelar pelo bem-estar físico e espiritual dos pacientes, representando a essência do seu trabalho.

\section{Jornada de trabalho}

Os depoimentos são unânimes quanto ao desgaste que representa trabalhar em uma organização hospitalar que funciona 24 horas por dia, 365 dias do ano, em um trabalho contínuo que se depara com sérios problemas de coordenação e operacionalização dos turnos e horários de trabalho.

Em seus depoimentos, os entrevistados do diurno confirmam que a jornada de seis horas diárias e os plantões de $12 \times 60 \mathrm{~h}$ são considerados muito dinâmicos e prazerosos em função da grande concentração de atividades de enfermagem nesse período, referentes à execução de procedimentos especiais, banhos no leito, administração de medicação e alimentação, dentre outras.

Já o turno da tarde apresenta um fluxo de trabalho menor, aparentemente mais monótono e ocioso, dando a sensação de que o tempo não passa. O pessoal entra em pânico no que concerne à possibilidade de vir trabalhar à noite, por julgar ser um horário que leva a um desgaste excessivo.

A jornada de trabalho noturna é percebida por muitos trabalhadores como excessivamente fatigante, prejudicando seu rendimento, saúde e bem-estar, assim como sua vida familiar e social, situação essa complicada pela associação à necessidade de realizarem o trabalho doméstico e, muitas vezes, terem outro emprego.

"Eu tenho dificuldade de concentração pra dormir, tenho deficiência de sono... eu tenho sono, sinto sono, eu deito na cama e não consigo relaxar. Eu já 'tive em vários neurologistas e eles passam medicações fortes assim, pra eu dormir e não vale nada, fico sem dormir... a gente vai levando, vou levando bobo..." (Técnico de Enfermagem - Entrevista 04)
A maioria dos entrevistados apontou o trabalho realizado à noite como gerador de transtornos fisiológicos relacionados com distúrbios do sono, agravados pelo fato de não conseguirem ter um repouso adequado após o plantão pelos ruídos e luminosidade do ambiente doméstico, além de perturbações do apetite e problemas digestivos. Demonstram que a falta de substitutos de folgas, férias e licenças conduz a uma sobrecarga de trabalho e um ritmo intenso que origina esgotamento e angústia, prejudicando-os sobremaneira por ocasião da ocorrência de faltas ao plantão. Nessas situações, o stress se faz presente, associado ao acúmulo de atividades e ao excesso de pacientes sob a responsabilidade de cada um, bem como à falta de ação eficaz em situações críticas pela dificuldade de concentração, cansaço e desatenção.

\section{O contato com a morte}

Os entrevistados falam que a maior parte de suas vidas profissionais transcorre em contato direto com o homem-paciente e suas necessidades. Desse contato, o mais doloroso, angustiante e difícil é com o paciente terminal, pois o enfrentamento da morte interfere diretamente em seus sentimentos, emoções e defesas.

Os depoimentos revelam que, ao assistir o morrer dos pacientes, os trabalhadores de enfermagem ficam frustrados, exibindo uma sensação de tristeza e lamento pela perda daquele alguém com quem se acostumaram a conviver. Tal percepção emerge no seguinte comentário:

"Ah! Quando morre um, acaba com o meu dia, aquilo me desequilibra toda, até eu chegar outra vez aonde eu estava... praticamente vai... a gente assim... é horrível." (Técnico de Enfermagem - Entrevista 04)

Os entrevistados explicam, ainda, que a intensidade do sofrimento pela morte dos pacientes é diferenciada, levando-se em conta fatores como a idade, o diagnóstico e o prognóstico deles. Os trabalhadores de saúde são preparados para manter e recuperar a vida e, quando percebem que não conseguem preservá-la, sentem-se desiludidos e deprimidos, requerendo, em alguns casos, apoio psicológico, por não suportarem a perda de pacientes queridos, conforme relato de uma $\mathrm{E}$ :

"Eu já tive problemas, fiquei muito chorosa, triste, depressão mesmo, daí precisei recorrer a um psicólogo da Universidade, porque eu não enfrentava bem essas questões de morte, cada vez que um paciente ia a óbito, pacientes que eu tinha mais apego, mais tempo de convivência com eles, era muito difícil, muito complicado na minha cabeça." (Enfermeiro - Entrevista 15)

Alguns entrevistados disseram viver sentimentos de angústia, dúvida e raiva por acreditarem que falharam na prestação dos cuidados, seja por não terem sido esgotadas todas as alternativas para recuperar a vida dos pacientes, seja por negligência de outros membros da equipe de saúde ou, ainda, por falta de condições materiais: 
"Quando um paciente morre porque ocorreu uma negligência, que a gente sabe disso... que existe... né? Isso choca muito a gente." (Técnico de Enfermagem - Entrevista 16)

Em síntese, constatamos que o hospital não é apenas o lugar onde as pessoas se tratam e se curam; é, também, onde morrem e onde, paradoxalmente, a palavra morte é negada. No HU-UFJF, um número relevante de entrevistados mostrou que seus pacientes não morrem: eles "expiram", "sucumbem", "falecem", "vão a óbito" ou "têm uma parada", expressões que indicam as dificuldades no convívio e no enfrentamento dessa situação.

\section{Envolvimento e afeto}

A contradição trabalhar para cuidar/tratar/curar versus trabalhar para sobreviver afeta de forma profunda a identidade do trabalhador de enfermagem e a relação afetotrabalho, conforme depoimentos colhidos com os entrevistados. Ressaltam que o apaziguamento dessa contradição, por meio do discurso ideológico ilustrado nos slogans ("a enfermagem é um sacerdócio", "a enfermagem é uma profissão que exige sacrifício, devoção, generosidade"), não surte mais efeito, tendo em vista o nível de consciência que adquiriram em face da deterioração das condições de trabalho e de vida, que demanda a busca de uma revalorização da profissão.

As contradições que o trabalho de cuidar impõem na percepção dos entrevistados envolvem, por um lado, a expressão de afeto e dedicação de que se precisa dispor na relação com o paciente ao lidar com a sua dor, sua dependência e sua intimidade; por outro lado, esse cuidado é mediado por três fatores complicadores e imbricados: o salário, fonte de sobrevivência; o fantasma da perda do paciente, seja por alta-cura, seja por alta-óbito, e a obrigação de se postar diante do paciente sempre como profissional, não lhes sendo permitido expressar suas angústias, tristezas, preferências ou recusas por esse ou aquele paciente.

\section{CONSIDERAÇÕES FINAIS}

As idéias expostas neste estudo evidenciaram o processo de desgaste/prazer no trabalho e os fatores que, na percepção dos trabalhadores da área de enfermagem, têm implicações nos sentimentos de prazer e desgaste no trabalho. Desde o início, buscamos a articulação desses fatores com o trabalho em si, sua organização e suas condições no ambiente hospitalar para o desenvolvimento das atividades laborais no âmbito do HU-UFJF. Este estudo leva-nos às conclusões e recomendações relatadas a seguir.

Em primeiro lugar, podemos afirmar que, apesar do sofrimento que contém em si, a atividade de enfermagem possibilita experimentar um prazer verdadeiro e concre- to, residindo a essência do sofrimento narrado pelos entrevistados na organização do trabalho e, primordialmente, nas condições de trabalho.

Nesse caso, como afirma Dejours (1992b), o sofrimento adquire um sentido - o prazer no trabalho é um produto derivado do sofrimento, pois, se, por um lado, os trabalhadores se empenham em lutar contra o sofrimento, por outro, não buscam situações de trabalho isentas de sofrimento, chegando até a detestá-las. Enfrentam sem hesitação as adversidades das situações de trabalho. Constatamos que a realidade de trabalho no HU-

\section{IDENTIFICAMOS UMA PROFISSÃO}

\author{
REPLETA DE CONTRADIÇÕES: UM \\ OFÍCIO RELEVANTE, PORÉM AINDA
}

INCAPAZ DE GERAR RECONHECIMENTO SOCIAL; UM FAZER EFICIENTE, MAS DESACOMPANHADO DE UM SABER COERENTE; UM FAZER NECESSÁRIO, MAS DESVALORIZADO E FRAGMENTADO; UM SABER IMPORTANTE, MAS UM FAZER PEQUENO.

UFJF é um terreno propício para jogar e rejogar com o sofrimento, apesar das situações críticas e das dificuldades que vivenciam. Todavia, quando se atende à demanda de assistência o mais próximo da normalidade e com um nível de qualidade aceitável, os entrevistados se sentem satisfeitos e recompensados, torna-se possível experimentar a sensação de se considerarem úteis e de estarem cumprindo o dever assumido com os mais fracos e dependentes.

Por outro lado, alguns entrevistados relataram desconforto mental ou psicossomático devido a frustrações, medo, cobranças, aborrecimento e sentimento de impotência diante da inexistência de condições organizacionais para se prestar um atendimento considerado ético e responsável aos pacientes. Tal ocorrência despontou como um dos grandes impeditivos do prazer no trabalho.

Em segundo lugar, ficou evidenciado, por meio dos relatos, o fato de a instituição apresentar traços incontestes ou significativos do modelo funcionalista/burocrático de gestão que, acrescidos de determinadas práti- 
cas tayloristas, fazem emergir problemas de saúde e segurança envolvidos na gênese do sofrimento no trabalho. Há uma ênfase muito forte na autoridade racionallegal, especialização/estanquização, rígida hierarquia vertical e sistemática divisão do trabalho, bem como apego às normas, regulamentos e regras que conduzem a um comportamento rotinizado e padronizado, fazendo com que os trabalhadores resistam a qualquer tipo de mudança. Identificamos, portanto, a existência de bloqueio na relação homem-organização do trabalho na área de enfermagem, haja vista a caracterização da prática de trabalho expressa pelos entrevistados, na qual se evidenciaram um alto grau de rigidez, a inflexibilidade e a ausência de liberdade e criatividade.

Em terceiro lugar, referindo-se especificamente às condições de trabalho no HU-UFJF, os trabalhadores de enfermagem demonstram que, sem escolha, se submetem-se às relações, condições e ambientes de trabalho geradores de insalubridade e penosidade, colocando-se diante de riscos ocupacionais diversos que favorecem o aparecimento de acidentes, sofrimento e doenças.

Baseados nos discursos dos trabalhadores de enfermagem, sujeitos da pesquisa, identificamos uma profissão repleta de contradições; um ofício relevante, porém ainda incapaz de gerar reconhecimento social; um fazer eficiente, mas desacompanhado de um saber coerente; um fazer necessário, mas desvalorizado e fragmentado; um saber importante, mas um fazer pequeno; um saber e um fazer marcados tanto pelo prazer quanto pelo desgaste/ sofrimento.

Em quarto lugar, chegamos à conclusão de que a trajetória da enfermagem de anjo de branco a profissional tem sido marcada por conflitos, preconceitos, desgaste, sofrimento e luta por espaço laboral. Abandonando a posição de um saber periférico e vulnerável, assistimos, atualmente, ao esforço dos trabalhadores de enfermagem para a construção de uma nova imagem que contempla estratégias de revalorização do estatuto profissional, controle da formação, das carreiras e dos conteúdos do trabalho para que se tornem agentes privilegiados e ativos na melhoria das condições de saúde da comunidade e propulsores, juntamente com os outros membros integrantes da equipe, da modernização e do avanço da gestão nas organizações hospitalares.

Por fim, considerando-se que os resultados obtidos pela análise dos depoimentos constitui uma representação relevante das percepções dos trabalhadores de enfermagem do hospital estudado, no que diz respeito à relação prazer e dor no trabalho que executam, sugerimos expandir os limites deste estudo para outras categorias da área de saúde, bem como para categorias fora da profissão e do contexto abordados, de modo a possibilitar uma compreensão mais abrangente da relação homem-trabalho, desgaste-prazer. $\bigcirc$
REFERÊNCIAS BIBLIOGRÁFICAS

DEJOURS, C. A loucura do trabalho: estudo de psicopatologia do trabalho. São Paulo : Cortez-Oboré, 1992a.

DEJOURS, C. Uma nova visão do sofrimento humano nas organizações. In: CHANLAT, J. F. (Coord.). O indivíduo na organização: dimensões esquecidas. São Paulo : Atlas, 1992b.

DEJOURS, C., ABDOUCHELI, E. Itinerário teórico em psicopatologia do trabalho. In: DEJOURS, C., ABDOUCHELI, E., JAYET, C. Psicodinâmica do trabalho: contribuições da escola dejouriana à análise da relação prazer, sofrimento e trabalho. São Paulo : Atlas, 1994.

FISCHER, R. M. "Pondo os pingos nos is" sobre as relações de trabalho e políticas de administração de recursos humanos. In: FLEURY, M. T. L., FISCHER, R. M. Processo e relações do trabalho no Brasil. São Paulo: Atlas, 1987
FLEURY, M. T. L., FISCHER, R. M. (Coords.). Processo e relações do trabalho no Brasil. São Paulo : Atlas, 1987.

LAURELL, A. C. Saúde e trabalho: os enfoques teóricos. In: NUNES, E. D. (Org.). As ciências sociais em saúde na América Latina: tendências e perspectivas. Brasília : OPAS, 1985.

LAURELL, A. C., NORIEGA, M. Processo de produção e saúde: trabalho e desgaste operário. São Paulo: Hucitec, 1989.

LOPES, G. T., SPÍNDOLA, T., MARTINS, E. R. I. 0 adoecer em enfermagem segundo seus profissionais. Revista de Enfermagem da UERJ, Rio de Janeiro, v. 4, n. 1, p. 9-18, 1996.

MENZIES, I. O funcionamento das organizações como sistemas sociais de defesa contra ansiedade. São Paulo: FGV, s.d. Mimeo.
ODDONE, I. et al. Ambiente de trabalho: a luta dos trabalhadores pela saúde. São Paulo : Hucitec, 1986.

PITTA, M. F. Hospital: dor e morte como ofício. São Paulo : Hucitec, 1990

SILVA, V. E. F. O desgaste do trabalhador de enfermagem: estudo da relação trabalho de enfermagem e saúde do trabalhador. Tese (Doutorado) - Escola de Enfermagem, Universidade de São Paulo, 1996.

SIQUEIRA, M. M. de. Relações de trabalho em hospitais de Belo Horizonte. Tese (Professor Titular) - Faculdade de Ciências Econômicas, Universidade Federal de Minas Gerais, 1991 